[Frontiers in Bioscience E2, 1-12, January 1, 2010]

\title{
Molecular interactions in extracellular matrix of tendon
}

\section{Evgenia Karousou ${ }^{1}$, Mario Ronga ${ }^{2}$, Davide Vigetti ${ }^{1}$, Daniele Barcolli ${ }^{2}$, Alberto Passi ${ }^{1}$, Nicola Maffulli ${ }^{3}$}

${ }^{I}$ Department of Experimental Biomedical and Clinical Sciences (DSBSC), University of Insubria, Varese, Italy, ${ }^{2}$ Department of Orthopaedic and Traumatology, University of Insubria, Varese, Italy, ${ }^{3}$ Department of Trauma and Orthopaedic Surgery, Keele University School of Medicine, Stoke on Trent, Staffordshire, UK

\section{TABLE OF CONTENTS}

1. Abstract

2. Introduction

3. Tendon ECM

3.1. Tendon components

3.2. Metabolism of collagen and other extracellular matrix proteins

3.2.1 Structures

3.2.2 GAG

3.2.3 Turn-over

3.2.4 ECM

4. Tendon nutrients supply

5. Functional role of ECM in tendon

6 From gene expression to tendon rupture

7. Perspectives

8. Aknowledgement

9. References

\section{ABSTRACT}

Tendon is a poorly vascularized and highly specialized connective tissue containing few scattered cells that play an important role in the musculoskeletal apparatus by resisting mechanical stress. Because of the slow rate of the metabolism of its molecular components, the tendon gradually loses its mechanical properties and may rupture upon an array of physical activities. In this report, we discuss the molecular changes involved in the extracelluar matrix-tendon interactions leading to tissue degeneration and rupture.

\section{INTRODUCTION}

Cells are closely connected to each other in all tissues and their cross-talk allows appropriate biological tissue function. Cells are organized in specialized structures responsible for particular mechanical properties, size and shape. The extracellular matrix (ECM) is a specialized environment surrounding all structures, and interacts with various cells. The ECM plays a pivotal role in maintaining efficient tissue function and organ development. However, it undergoes several changes during the pathological process, and impact the biomechanical behaviour of the 
tendon. The importance of the ECM is evidenced by the interaction of hydrophilic and hydrophobic molecules to confer specific characteristics to the intercellular milieu; this feature determines the mechanical tissue properties of bone tissue or an elastic organ such as lung. Although the ECM of these tissues contains fibrillar collagen type I mainly, the bone ECM composition and organization provide rigid mechanical properties to the tissue. In contrast, the ECM of an elastic organ, such as lung, has a different molecular composition that determines its specific mechanical properties. Thus, the mechanical properties of a tissue depend on the structural organization and the molecular composition of the ECM. However, ECM composition changes during the development stages of the same tissue. As an example, glycosaminoglycan (GAG) cartilage composition changes dramatically during aging in all mammals, suggesting that GAG can be used as a marker of cartilage aging. Moreover, the number of different molecules is an additional variable to consider in defining a specific tissue.

Tendons and ligaments are dense, regularly arranged, connective tissues that support joint movement (1). The mechanical properties of tendon ECM provide a functional link between skeletal muscle fibers and the bone, playing a critical role in force displacement. Contractile filaments in skeletal muscle react to force development whereas the adjacent tendon tissue shows a passive structure allowing joint movement (2-5). Signals from mechanical movement can trigger a cascade of molecular events, including gene expression, transcription, translation and posttranslational modifications, leading to changes in tendon proteins (6). However, these events are poorly understood in tendon ECM compared to other tissues.

In addition to describing the structural and functional properties of tendon ECM, this review will discuss the gene expression changes that drive a healthy tendon to rupture.

\section{ECM IN TENDON}

Synthesis of the components of the tendon occurs in fibroblasts. Studies using isolated tendon fibroblasts showed that fibroblasts respond to mechanical stress, and release several components of the ECM (7). Cells in a healthy tendon are associated through gap junctions as revealed by immunolabeling for connexin 32 and connexin43 (8-9). In the tendon, the architectural interconnection of fibroblasts forms a three-dimensional network surrounding the collagen fibrils, which provides a basis for cell-to-cell interaction. Under mechanical cyclic loading, tendon cells upregulate collagen and gap junction production, whereas pharmacological inhibition of the gap junction abolishes this response (10). The ECM encompasses various molecules of which collagen fibrils and proteoglycans (PGs) are the major components. In addition to PGs, the hydrophilic ECM includes a variety of other proteins such as noncollagen glycoproteins (11-12). ECM integrity is necessary for tendon function during muscle-tendon complex force transmission and tendon fibrillar arrangements (13-14).
Matrix tensile strength depends on intra- and inter-molecular crosslinks, orientation, density, and length of both collagen fibrils and fibers, indicating that the integrity at molecular level is the critical part of the architecture (15). However, very little is known about the growth of connective tissue cells under mechanical loading as well as the expression and synthesis of specific ECM proteins (7).

\subsection{Tendon components}

Tendons consist of 55-70\% water with a systematic and densely packed connective tissue (16). Collagen is its major component $(60-85 \%$ of tendon dry weight), organized into fibrils, fibers, fiber bundles and fascicles, and it forms $20-25 \%$ of ECM proteins. The predominant form, type I collagen $(60 \%)$, is arranged in tensile-resistant fibers. It is composed of two alphal and one alpha 2 chains, which are products of separate genes rather than a posttranslational modification of a single molecule. Other ECM molecules are also present in the tendon, including collagen types III, IV, V and VI (less than $10 \%$ ) (17), PGs and other glycoproteins (18). Collagen synthesis/degradation is measured indirectly by determining the collagen peptides produced during the different steps of collagen biosynthesis and catabolism. Pro-collagens contain amino terminal and carboxy terminal extension peptides at the respective ends of the collagen molecule. After secretion, the amino-propeptides are cleaved by specific proteinases and the collagens selfassemble into fibrils or other molecular structures. While pro-collagen release and turnover have been extensively studied in the bone, these mechanisms are not well explored in the tendon (19).

The non fibrous component of the tendon is characterized by PGs, namely small leucine-rich proteins of which decorin (up to $1 \%$ ) is the main molecule (11). Also, tendon tissue contains other small leucine-rich PGs such as fibromodulin, biglycan (up to $0.5 \%$ ) and lumican, together with cartilage oligomeric matrix protein (COMP, less than $1 \%$ ), osteoadherin, tenascin-C, proline arginine-rich and leucine-rich repeated proteins, optican, keratocan, epiphycan, syndican, perlecan, agrin, fibronectin, laminin, vercican and aggrecan (20-23). PGs contain sulphated polysaccharide chains or glycosaminoglycan (GAG), macromolecules that are widely distributed in nature showing great variability in structure and function. PGs are vital in tissue structure maintenance and differentiation, especially articular cartilage. Like the majority of polysaccharide chains, PG functional peculiarities depend on their structural complexity. They contain a core protein coded by a single gene and at least one sulphated polysaccharide chain, GAG. GAGs are covalently linked to the core protein and show a wide variety of chemical species and structures. For these reasons, GAGs are classified as galactosaminoglycuronan (dermatan sulphate and chondroitin sulphate) and glucosaminoglycuronan (heparansulphate and heparin). Glucuronic acid covalently linked to a mono-or di-sulphated hexosamine constitutes the disaccharide units. Hyaluronan (HA) is the only GAG without core protein and sulphated hexosamine. The core proteins have been studied in depth and their gene 
sequence, splicing variants and cristallographic properties have been characterized, emphasizing the vital functional role of PG core protein (24-27). PGs seem to interact with several ECM molecules, primarily growth factors, in healthy and pathological conditions, playing an important role in tissue metabolism.

\subsection{Metabolism of collagen and other extracellular matrix proteins \\ 3.2.1. Structures}

Collagen is synthesized and secreted by fibroblasts, and undergoes co- and post-translational modifications, which contribute to the quality and stability of the collagen molecule. In the cell, the C-propeptide domains of polypeptide alpha-chains fold and the trimerization process leads to the formation of fibrillar collagen types. The gene coding pro-collagen chains encompasses large intronic and exonic DNA sequences, which requires extensive RNA processing for protein synthesis (28). Pro-collagens are transferred from ER to the extracellular space through the Golgi apparatus and contain amino-terminal and carboxy-terminal extension peptides at the respective ends of the collagen molecule (29). Procollagen requires peculiar transport within the Golgi apparatus, being larger than the conventional transport vesicles (30). After secretion into the extracellular space, the amino-propeptides are cleaved by specific proteinases and the collagens self-assemble into fibrils or other molecular structures (31). Following the transcription of genes coding for collagen type I formation, the initially synthesized pro-alpha-chains undergo posttranslational reactions. At the outset hydroxylation converts residues to 4-hydroxyproline or 3-hydroxyproline by three different hydroxylases (32). Hydroxylases are specific enzymes that act on non-helical substrates. Therefore they do not affect collagen or collagen-like peptides that are triple helical structures. Newly synthesized collagen polypeptides are glycosylated and this process ends before the collagen is folded into a triple helix structure. The intracellular processing leads to the synthesis of both intrachain and interchain disulfide bonds (33), and secretion of procollagen. The three polypeptide chains form a triple-helical structure, and the alpha-chains, forming the structure, are composed of repeating aminoacid sequences Gly-X-Y, where the glycine residue enables the three alpha-chains to coil the polypeptide chain. Proline and 4-hydroxyproline residues appear frequently at the $\mathrm{X}$ - and Y-positions, respectively, and promote the formation of intermolecular cross-links. The stability and quality of the collagen molecule is largely based on the intra- and inter-molecular cross-links. A unique feature of collagen is that 4hydroxyproline formation is catalyzed by $\mathrm{P}-4-\mathrm{H}$, indicating that it is a biomarker for evaluating collagen content. P-4-H activity is generally associated with collagen biosynthesis and has been used to estimate changes in the rate of collagen biosynthesis in various experimental and physiological conditions (34). Pro-collagen C-proteinase is identical to bone morphometric protein (BMP-1) (35). A more recent report described both intra- and extracellular pools of active procollagen C-proteinase (BMP-1) in embryonic chicken tendon fibroblasts, whereas the $\mathrm{N}$ proteinase (called ADAMTS-2) is located in close proximity to or within the plasma membrane (36). The block of C-proteinases stops the conversion of extracellular pro-collagen to collagen inducing an intracellular procollagen accumulation in post-Golgi.

Fibril segments are prerequisites for fibril formation, acting as primers and have been shown to increase in length gradually increasing diameter (37-40). Collagen molecules can be either unipolar or bipolar and fuse end to end (41-43). Although, cross-link deficient tendons are less resistant to loading and that tendon elongation depends on molecular cross-links within the collagen fibrils, the role of fibrillar structure in resistance to loading is not clear (44-46).

PGs play a critical role in fibrillogenesis and when decorin/fibronectrin binding is inhibited, tendon length increases (47-48). Pyridinoline (Pyr), a cross-link component of the ECM of mature collagen fibers, is critical to the formation of collagen structures (49). The ratio between Pyr and collagen is particularly high in tendon indicating that this parameter could be useful in the study of tendon metabolism.

\subsubsection{Glycosaminoglycan}

The GAG sulphated groups providing negative charges for PGs are critical for macromolecule function. While HA synthesis occurs in the cytoplasm, and HA synthases (HAS 1, 2 and 3) are located on the cell membrane, sulphated GAGs polymerization takes place in the Golgi apparatus where several polymerases cooperate with sulphotransferases to build polysaccharide chains. Sulphotransferases transfer a sulphate group from 3'phosphoadenosine 5'-phosphosulfate (PAPS) to a growing chain in the Golgi apparatus after the action of the PAPS transporter. The enzymatic machinery operates in the Golgi membranes to facilitate the biosynthesis of sulphated sugar chains, similar to the process of HS/heparin biosynthesis where glucuronyl C5-epimerase interacts with heparansulphate (HS) 2-O-sulphotransferase (HS2ST) (50). Glycan sulphation by Golgi-resident sulphotransferases is now recognized as a major regulatory mechanism. Glycan sulphation is known to affect glycoprotein hormone pharmacokinetics, growth factor and cytokine activity, and viral and bacterial adhesion (51-55). While the PGs and water provide space and lubricating properties for the tendon, the precise role of the small non aggregating leucine-rich PGs remains unclear. The PGs also seem to play an important role in fibril fusion, as do fibrillin molecules aligning along fibrils (56).

\subsubsection{Turn-over}

Carboxypeptide cleavage allows indirect determination of collagen type I formation. Development of assays to determine markers for synthesis of type I collagen (the $\mathrm{COOH}$-terminal propeptide of type I collagen (PICP)) and degradation (the $\mathrm{COOH}$-terminal telopeptide region of type I collagen (ICTP)) has offered the possibility to study the effect of mechanical stress on collagen type I turnover (57). The microdialysis technique demonstrated that acute exercise induces changes in metabolic and inflammatory activity in the peritendinous region (19). In addition, acute 
exercise induced a higher type I collagen formation in the recovery process, suggesting that acute physical loading leads to adaptations in human non-bone-related collagen. Like in the blood, values for PICP did not change significantly over the training period, suggesting that the increased collagen type I formation occurs locally in tendon, rather than reflecting a general increase in the formation of collagen type I in all tendons (58). The stimulation of synthesis and degradation of collagen in tendon in response to exercise is associated with the events occurring after muscle exercise (59). An increased collagen turnover was observed in response to training and a net synthesis of collagen type I occurs in tendon with prolonged training. Using magnetic resonance imaging (MRI), the Achilles tendon cross-sectional area was enlarged in trained individuals compared to untrained controls (60).

Collagen turnover in the tendon is comparable to that in the bone (61-62). Therefore, the load leads to a higher increase in tendon collagen type I synthesis than the increase of muscle type IV collagen synthesis. Similar results were obtained measuring other non-collagen tendon proteins synthesized after loading, indicating that the tissue response involves all ECM proteins $(7,23,63)$. On the other hand, immobilization leads to reduced collagen synthesis, and subsequent decrease in the enzyme activities of collagen biosynthesis in both skeletal muscle and tendon (64-65), suggesting that collagen biosynthesis decreases with inactivity (66). Gene expression experiments suggest that the rate of collagen expression during immobilization is partially downregulated at the pre-translational level (67). An early decrease of mRNA expression for collagen type Is, III, and I was evident after 3 days of immobilization (68).

\subsubsection{ECM}

ECM protein balance is regulated by synthesis and degradation of ECM components (69-71). Several proteolytic enzymes are involved in matrix degradation, metalloproteases (MMPs) being the most important molecules. MMPs are a family of zinc- and calciumdependent endopeptidases involved in remodeling the normal ECM connective tissue. Collagen degradation is a critical step in turnover and remodeling of connective tissue as well as tendon healing, and it is initiated extracellularly by MMPs (or matrixins) present mainly as latent proMMPs (72-74). Using rat model, MMP-9 and MMP-13 were involved in collagen degradation only, whereas MMP-2, MMP-3 and MMP-14 were implicated in both collagen degradation and remodeling (75). The endogenous activity of MMPs is normally inhibited by the endogenous tissue metalloprotease inhibitors (TIMPs). The metabolic balance between the activities of endogenous MMPs and TIMPs is responsible for the normal remodeling of tendon. However, excess of MMP activity can lead to progressive degeneration and weakening of the tendon's ECM. Erlichman and co-workers demonstrated that MMPs act extracellularly without any involvement in the major intracellular lysosomal proteolytic machinery (76). Tendon collagen degradation is described as a consequence of inflammatory processes, tissue damage or development (77-79).

Collagenases (MMP-1 and MMP-8), degrading collagen type Is and III, are the most important enzymes for tendon metabolism. Gelatinases (MMP-2 and MMP-9) can digest non fibrillar collagen and other ECM compounds (80). However, MMP-2 can also degrade type I collagen, most likely in a two-step fashion (81-82). MMPs are present in the musculotendineous apparatus, being produced from fibroblasts of the endotenon and intramuscular matrix. The immobilization leads to an increase in MMP gene expression at both pre- and posttranslational levels, suggesting accelerated collagen breakdown. Recent experimental evidence showed that acute exercise induced an elevated interstitial accumulation of MMP-2 and MMP-9 in human peritendinous tissue supporting the idea that MMPs (and their inhibitors) play a pivotal role in ECM adaptation to exercise in tendon tissue (83). Furthermore, MMP-1 expression can be modulated by growth factors, inflammatory cytokines and cytoskeletondisrupting drugs like cytochalasin D, and MMP-1 gene expression can be stimulated by an IL-1 autocrine feedback loop (84-85).

Four different TIMP molecules have been identified so far (86). TIMP-1 and TIMP-2 are the most common and inhibit the activities of all MMPs with a preference for MMP-9 and MMP-2, respectively. TIMP-2 is not only involved in MMP2 inhibition, but acts as a docking element exposing pro-MMP-2 to MT1-MMP that cleaves the pro-peptide to activate MMP2 (87). After exercise, TIMP expression is upregulated at the pre- and post-translational levels, suggesting an increase in collagen degradation coupled with collagen synthesis (88-89). These findings indicate that concomitant stimulation and inhibition of ECM degradation occurs during exercise suggesting that TIMPs regulate ECM degradation.

\section{TENDON NUTRIENTS SUPPLY}

Compared with muscle, tendons have a poorly developed vasculature, and the area occupied by vessels represents $1-2 \%$ of the entire ECM (90). The vessels mainly stem from the epitendon where they run longitudinally into the endotendon (91). Feeding arteries and arterioles may come from the perimysium at the musculotendinous junction and vessels from the tendon bone junction (92). However, how blood flows in different conditions of tendon remains poorly understood. For example, rabbit tendons have $1 / 3$ of muscle blood flow during inactivity, whereas blood flow increases both in ligaments and tendons during activity and tissue healing (93). Different human models have shown a blood flow increase up to sevenfold within and around tendon during exercise in young, middle aged and elderly subjects. Tendon blood flow is regulated independently, implying a refined balance in different mechanical situations (94-98). However, the role of ECM in regulating blood flow and vessel diameter is not clear. An increase in adenosine concentration, intensity-dependent, was observed in the muscle, but tendon modifications were not significant and 
unrelated to intensity (99). Furthermore, bradykinin concentrations showed parallel increase in the both tissues during exercise, and its maximal response was recorded at low exercise loads (99). These two substances are involved in skeletal muscle and tendon blood flow regulation during exercise. Whether bradykinin has a vasodilatory effect on the vasculature, directly or indirectly via release of other substances such as nitric oxide (NO), prostaglandins or endothelium derived hyperpolarizing factor (EDHF), is yet to be established (100-103).

There is no evidence that the blood flow increase is sufficient to meet the oxidative needs of the tendon during exercise $(94,104,105)$. There is a correlation between increasing tendon blood flow and declining oxygen tissue saturation, indicating that the estimated oxygen uptake in human tendon increases significantly during exercise compared to the resting state (106).

\section{FUNCTIONAL ROLE OF ECM IN TENDON}

Together with muscles, tendons act to transmit the contraction force (107-109). Although several ECM molecules, in addition to collagen, have been located in tendon and muscle, little is known about their functional role. The use of knock-out (KO) mice models helped elucidate the role of ECM molecules in the muscle and tendon. A mix of alterations was shown using these models in various connective tissues such as the development of severe osteogenesis imperfecta in type I collagen $\mathrm{KO}$ mice (110). The lack of laminin, collagen type VI and integrins altering the basal membrane structures, induces muscle dystrophy and myopathy (111). Irregular collagen fibrils were observed in tendon structure using fibromodulin-null mice models to study proteoglycan defects, whereas no changes were detected in bone or cartilage (112). Mice KO for biglycan and fibromodulin showed ectopic tendon ossification (113). Interestingly, mice lacking COMP showed no clear musculotendinous abnormalities, whereas COMP deficiency in humans causes skeletal dysplasia (114).

PGs play a critical role in the ECM molecules interaction (115-117). Decorin KO prevents any lateral fusion of collagen fibrils, indicating its involvement in collagen fibril formation and diameter control $(47,115)$. The inhibition of decorin results in larger collagen fibrils and increased mechanical properties in healing ligaments (118). The role of decorin and the fibromodulin or lumican are not fully understood (119-121). In chicken embryonic tendon, small leucine-rich PGs like decorin are bound to collagen even prior collagen fibril assembly, suggesting complex effect of these PGs in collagen synthesis (41).

It is not surprising that the PG composition in tendon can change in different physiological conditions. Aggrecan, the large chondroitin sulfate PG, is largely upregulated after tendon mechanical loading, whereas decorin only responds to tensile loading $(63,122)$. This could explain why type II collagen is found in tendon regions subjected to compressive forces $(9,123,124)$. Several observations confirm these findings, including the increase in larger weight of PGs in tendons in response to compressive stress (125-126). Thus this data illustrate the differentiated response to tensile and compressive loading, respectively, on collagen and ECM PGs (127-128).

\section{FROM GENE EXPRESSION TO TENDON RUPTURE}

Spontaneous tendon rupture and chronic tendon pain are common events. However, the underlying pathological process is not well understood and hence current treatment is not effective in all cases. A genetic component has been implicated in several tendinopathies that could explain why there is an increased risk of contralateral rupture of the Achilles tendon in subjects with previous rupture (129). Tendinopathy may develop due to the interaction between a particular genetic configuration and the various intrinsic and extrinsic factors affecting tendon health (130). Histopathological studies have revealed that inflammatory processes were substantially absent, as was cell infiltration. Nevertheless, many ECM degeneration aspects were evident including loss of collagen fiber organization, decreased fibril diameter, changes in cell density (both increased and decreased), cell rounding, GAG accumulation, lipid accumulation and calcification (131-133). Although similar alterations were found in normal tendons, they are generally less severe, and it is assumed that ECM degeneration precedes the onset of clinical symptoms (134). Collagen total content was decreased whereas collagen type III showed a relative increase in ruptured tendons (135). These collagen changes are coupled with an increase in crosslinks related to gradual accumulation of type III collagen over a relatively long time period, allowing maturation of collagen crosslinks and stabilization of the ECM (136). As a result, the gradual incorporation of type III collagen into the main fibre bundles is consistent with a reduction in average fibril diameter (137). These molecular alterations reduce the tendon's capacity to resist stress, and are involved in tendon rupture (138). In addition, other biochemical studies have shown an increase in the amount of HA and various PGs in degenerated tendons $(17,139)$. Increased hydrophilic polymer such as HA induces a high water concentration. Molecular approaches such as PCR and microarray analyses have provided relevant information on gene expression in tendinopathy (140-142). Ireland and coworkers found 23 genes upregulated and 17 genes downregulated in degenerated Achilles tendon (140). Proteomic Validation studies are underway to verify the presence or absence of the corresponding proteins. Interestingly, no changes in the expression of cytokines and their receptors were observed, indicating the absence of any ongoing inflammatory process, as confirmed by analysis of the fluids surrounding painful tendons (143). Alteration of ECM at molecular level is the key element of tendon pathology, and in this context the expression of proteolytic activities and their effects on tendon ECM turnover are critical. While the precise role of MMPs in tendinopathy remains to be determined, several MMPs have been identified in acute tendon injuries, showing different timing and location of expression (144). The expression levels of MMP-9 and MMP-13 were high one and two weeks after 
injury, whereas MMP-2, MMP-3 and MMP-14 were highly expressed after four weeks (75). It appears that MMP-9 and MMP-13 are involved in collagen degradation during the initial inflammatory phase, whereas MMP-2, MMP-3 and MMP-14 play a critical role in scar tissue remodelling. The absence of MMP-1 and MMP-8 expression was associated with absence of inflammation. In addition, while MMP-9 and MMP-13 were detected only in ruptured tendons, small but variable increase in MMP-2 and MMP-14 was observed in degenerated tendons (140-143). MMP-3 activity showed the greatest difference between normal and pathological tendon specimens (140-143). In fact, a remarkable loss of MMP-3 activity has been reported in tendinopathy which may cause an increase in PGs. However, PG degradation is attributed to aggrecanases, and it is still unclear how the decrease of MMP-3 could be associated with an increase in PG content (80). Because PG levels are increased in degenerated tendon lesions (unlike osteoarthritis), it would be interesting to see whether this is due to enhanced synthesis or decreased degradation of PGs.

Tendons are frequently affected by chronic pain or rupture, and many causative factors implicated in their pathology remained unexplored until recently. Tendinopathy is mainly associated with degeneration, which is thought to be an active, cell-mediated process involving an increased turnover and remodelling of the tendon ECM (145). Neuropeptides and other factors released by stimulated cells or nerve endings in or around the tendon might influence matrix turnover and could provide new targets for therapeutic intervention.

\section{PERSPECTIVES}

This review focuses on the critical role of ECM, namely collagen, in the tendon-muscle interaction and adaptation to mechanical loading, and the effect of these stimuli on ECM composition at molecular level. In contrast to the view of the ECM as a static and inert portion of the tendon, several studies have introduced the concept that ECM is a dynamic structure that adapts to a variety of functional demands. Further studies could clarify the relation between the different ECM molecules and the balance between catabolic and anabolic processes.

\section{AKNOWLEDGEMENT}

This work was supported by funds from "Fondazione Comunitaria Onlus Varesotto" to D.V.

\section{REFERENCES}

1. M. Khatod and D. Amiel: Ligament biochemistry and physiology. Lippincott Williams and Wilkins, Philadelphia (2003)

2. M. Kjaer: Role of extracellular matrix in adaptation of tendon and skeletal muscle to mechanical loading. Physiol Rev, 84, 649-98 (2004)

3. H. E. Huxley: The mechanism of muscular contraction. Science, 164, 1356-65 (1969)
4. R. M. Alexander and H. C. Bennet-Clark: Storage of elastic strain energy in muscle and other tissues. Nature, 265, 114-7 (1977)

5. P. A. Huijing, G. C. Baan and G. T. Rebel: Nonmyotendinous force transmission in rat extensor digitorum longus muscle. J Exp Biol, 201, 683-91 (1998)

6. T. Yasuda, S. Kondo, T. Homma and R. C. Harris: Regulation of extracellular matrix by mechanical stress in rat glomerular mesangial cells. J Clin Invest, 98, 1991-2000 (1996)

7. A. J. Banes, G. Horesovsky, C. Larson, M. Tsuzaki, S. Judex, J. Archambault, R. Zernicke, W. Herzog, S. Kelley and L. Miller: Mechanical load stimulates expression of novel genes in vivo and in vitro in avian flexor tendon cells. Osteoarthritis Cartilage, 7, 141-53 (1999)

8. C. M. McNeilly, A. J. Banes, M. Benjamin and J. R. Ralphs: Tendon cells in vivo form a three dimensional network of cell processes linked by gap junctions. J Anat, 189 ( Pt 3), 593-600 (1996)

9. J. R. Ralphs, M. Benjamin, A. D. Waggett, D. C. Russell, K. Messner and J. Gao: Regional differences in cell shape and gap junction expression in rat Achilles tendon: relation to fibrocartilage differentiation. J Anat, 193 ( Pt 2), 215-22 (1998)

10. A. J. Banes, P. Weinhold, X. Yang, M. Tsuzaki, D. Bynum, M. Bottlang and T. Brown: Gap junctions regulate responses of tendon cells ex vivo to mechanical loading. Clin Orthop Relat ResS356-70 (1999)

11. K. A. Derwin, L. J. Soslowsky, J. H. Kimura and A. H. Plaas: Proteoglycans and glycosaminoglycan fine structure in the mouse tail tendon fascicle. J Orthop Res, 19, 269-77 (2001)

12. J. E. Scott: Supramolecular organization of extracellular matrix glycosaminoglycans, in vitro and in the tissues. Faseb J, 6, 2639-45 (1992)

13. A. J. Bailey, G. B. Shellswell and V. C. Duance: Identification and change of collagen types in differentiating myoblasts and developing chick muscle. Nature, 278, 67-9 (1979)

14. R. M. Alexander: Energy-saving mechanisms in walking and running. J Exp Biol, 160, 55-69 (1991)

15. K. Barnard, N. D. Light, T. J. Sims and A. J. Bailey: Chemistry of the collagen cross-links. Origin and partial characterization of a putative mature cross-link of collagen. Biochem J, 244, 303-9 (1987)

16. D. H. Elliott: Structure and Function of Mammalian Tendon. Biol Rev Camb Philos Soc, 40, 392-421 (1965)

17. H. L. Birch, A. J. Bailey and A. E. Goodship: Macroscopic 'degeneration' of equine superficial digital 
flexor tendon is accompanied by a change in extracellular matrix composition. Equine Vet J, 30, 534-9 (1998)

18. M. Kjaer, H. Langberg, B. F. Miller, R. Boushel, R. Crameri, S. Koskinen, K. Heinemeier, J. L. Olesen, S. Dossing, M. Hansen, S. G. Pedersen, M. J. Rennie and P. Magnusson: Metabolic activity and collagen turnover in human tendon in response to physical activity. $J$ Musculoskelet Neuronal Interact, 5, 41-52 (2005)

19. H. Langberg, D. Skovgaard, L. J. Petersen, J. Bulow and M. Kjaer: Type I collagen synthesis and degradation in peritendinous tissue after exercise determined by microdialysis in humans. $J$ Physiol, 521 Pt 1, 299-306 (1999)

20. G. Muller, A. Michel and E. Altenburg: COMP (cartilage oligomeric matrix protein) is synthesized in ligament, tendon, meniscus, and articular cartilage. Connect Tissue Res, 39, 233-44 (1998)

21. T. A. Jarvinen, L. Jozsa, P. Kannus, T. L. Jarvinen, M. Kvist, T. Hurme, J. Isola, H. Kalimo and M. Jarvinen: Mechanical loading regulates tenascin- $\mathrm{C}$ expression in the osteotendinous junction. J Cell Sci, 112 Pt 18, 3157-66 (1999)

22. L. Jozsa and P. Kannus: Histopathological findings in spontaneous tendon ruptures. Scand J Med Sci Sports, 7, 113-8 (1997)

23. S. G. Rees, C. R. Flannery, C. B. Little, C. E. Hughes, B. Caterson and C. M. Dent: Catabolism of aggrecan, decorin and biglycan in tendon. Biochem J, 350 Pt 1, 181-8 (2000)

24. W. Sheng, G. Wang, Y. Wang, J. Liang, J. Wen, P. S. Zheng, Y. Wu, V. Lee, J. Slingerland, D. Dumont and B. B. Yang: The roles of versican V1 and V2 isoforms in cell proliferation and apoptosis. Mol Biol Cell, 16, $1330-40$ (2005)

25. R. V. Iozzo: Matrix proteoglycans: from molecular design to cellular function. Annu Rev Biochem, 67, 60952 (1998)

26. R. V. Iozzo: The biology of the small leucine-rich proteoglycans. Functional network of interactive proteins. $J$ Biol Chem, 274, 18843-6 (1999)

27. G. F. Guidetti, B. Bartolini, B. Bernardi, M. E. Tira, M. C. Berndt, C. Balduini and M. Torti: Binding of von Willebrand factor to the small proteoglycan decorin. FEBS Lett, 574, 95100 (2004)

28. E. Vuorio and B. de Crombrugghe: The family of collagen genes. Annu Rev Biochem, 59, 837-72 (1990)

29. R. Harwood, M. E. Grant and D. S. Jackson: The route of secretion of procollagen. The influence of alphaalpha'bipyridyl, colchicine and antimycin A on the secretory process in embryonic-chick tendon and cartilage cells. Biochem J, 156, 81-90 (1976)
30. L. Bonfanti, A. A. Mironov, Jr., J. A. MartinezMenarguez, O. Martella, A. Fusella, M. Baldassarre, R. Buccione, H. J. Geuze, A. A. Mironov and A. Luini: Procollagen traverses the Golgi stack without leaving the lumen of cisternae: evidence for cisternal maturation. Cell, 95, 993-1003 (1998)

31. D. J. Prockop, A. L. Sieron and S. W. Li: Procollagen $\mathrm{N}$-proteinase and procollagen C-proteinase. Two unusual metalloproteinases that are essential for procollagen processing probably have important roles in development and cell signaling. Matrix Biol, 16, 399-408 (1998)

32. J. Myllyharju: Prolyl 4-hydroxylases, the key enzymes of collagen biosynthesis. Matrix Biol, 22, 15-24 (2003)

33. K. J. Doege and J. H. Fessler: Folding of carboxyl domain and assembly of procollagen I. J Biol Chem, 261, 8924-35 (1986)

34. X. Y. Han, W. Wang, R. Myllyla, P. Virtanen, J. Karpakka and T. E. Takala: mRNA levels for alpha-subunit of prolyl 4-hydroxylase and fibrillar collagens in immobilized rat skeletal muscle. J Appl Physiol, 87, 90-6 (1999)

35. S. W. Li, A. L. Sieron, A. Fertala, Y. Hojima, W. V. Arnold and D. J. Prockop: The C-proteinase that processes procollagens to fibrillar collagens is identical to the protein previously identified as bone morphogenic protein-1. Proc Natl Acad Sci U S A, 93, 5127-30 (1996)

36. P. Bornstein: The NH (2)-terminal propeptides of fibrillar collagens: highly conserved domains with poorly understood functions. Matrix Biol, 21, 217-26 (2002)

37. D. A. Parry, A. S. Craig and G. R. Barnes: Tendon and ligament from the horse: an ultrastructural study of collagen fibrils and elastic fibres as a function of age. Proc R Soc Lond B Biol Sci, 203, 293-303 (1978)

38. D. A. Parry, G. R. Barnes and A. S. Craig: A comparison of the size distribution of collagen fibrils in connective tissues as a function of age and a possible relation between fibril size distribution and mechanical properties. Proc R Soc Lond B Biol Sci, 203, 305-21 (1978)

39. R. Fleischmajer, E. D. MacDonald, J. S. Perlish, R. E. Burgeson and L. W. Fisher: Dermal collagen fibrils are hybrids of type I and type III collagen molecules. J Struct Biol, 105, 162-9 (1990)

40. R. Fleischmajer, B. R. Olsen, R. Timpl, J. S. Perlish and O. Lovelace: Collagen fibril formation during embryogenesis. Proc Natl Acad Sci U S A, 80, 3354-8 (1983)

41. H. K. Graham, D. F. Holmes, R. B. Watson and K. E. Kadler: Identification of collagen fibril fusion during vertebrate tendon morphogenesis. The process relies on unipolar fibrils and is regulated by collagen-proteoglycan interaction. J Mol Biol, 295, 891-902 (2000) 
42. D. E. Birk and R. Mayne: Localization of collagen types I, III and V during tendon development. Changes in collagen types I and III are correlated with changes in fibril diameter. Eur J Cell Biol, 72, 352-61 (1997)

43. D. E. Birk, E. I. Zycband, S. Woodruff, D. A. Winkelmann and R. L. Trelstad: Collagen fibrillogenesis in situ: fibril segments become long fibrils as the developing tendon matures. Dev Dyn, 208, 291-8 (1997)

44. D. L. Christiansen, E. K. Huang and F. H. Silver: Assembly of type I collagen: fusion of fibril subunits and the influence of fibril diameter on mechanical properties. Matrix Biol, 19, 409-20 (2000)

45. M. E. Willems, G. R. Miller and W. T. Stauber: Force deficits after stretches of activated rat muscle-tendon complex with reduced collagen cross-linking. Eur J Appl Physiol, 85, 405-11 (2001)

46. P. Fratzl, K. Misof, I. Zizak, G. Rapp, H. Amenitsch and S. Bernstorff: Fibrillar structure and mechanical properties of collagen. J Struct Biol, 122, 119-22 (1998)

47. K. G. Danielson, H. Baribault, D. F. Holmes, H. Graham, K. E. Kadler and R. V. Iozzo: Targeted disruption of decorin leads to abnormal collagen fibril morphology and skin fragility. J Cell Biol, 136, 729-43 (1997)

48. P. A. Caprise, G. E. Lester, P. Weinhold, J. Hill and L. E. Dahners: The effect of NKISK on tendon in an in vivo model. J Orthop Res, 19, 858-61 (2001)

49. L. Knott, J. F. Tarlton and A. J. Bailey: Chemistry of collagen cross-linking: biochemical changes in collagen during the partial mineralization of turkey leg tendon. Biochem J, 322 ( Pt 2), 535-42 (1997)

50. M. A. Pinhal, B. Smith, S. Olson, J. Aikawa, K. Kimata and J. D. Esko: Enzyme interactions in heparan sulfate biosynthesis: uronosyl 5-epimerase and 2-Osulfotransferase interact in vivo. Proc Natl Acad Sci U S A, 98, 12984-9 (2001)

51. K. Honke and N. Taniguchi: Sulfotransferases and sulfated oligosaccharides. Med Res Rev, 22, 637-54 (2002)

52. J. U. Baenziger, S. Kumar, R. M. Brodbeck, P. L. Smith and M. C. Beranek: Circulatory half-life but not interaction with the lutropin/chorionic gonadotropin receptor is modulated by sulfation of bovine lutropin oligosaccharides. Proc Natl Acad Sci U S A, 89, 334-8 (1992)

53. H. Lortat-Jacob, A. Grosdidier and A. Imberty: Structural diversity of heparan sulfate binding domains in chemokines. Proc Natl Acad Sci U S A, 99, 1229-34 (2002)

54. D. Shukla, J. Liu, P. Blaiklock, N. W. Shworak, X. Bai, J. D. Esko, G. H. Cohen, R. J. Eisenberg, R. D. Rosenberg and P. G. Spear: A novel role for 3-O-sulfated heparan sulfate in herpes simplex virus 1 entry. Cell, 99, 13-22 (1999)
55. K. Pethe, S. Alonso, F. Biet, G. Delogu, M. J. Brennan, C. Locht and F. D. Menozzi: The heparin-binding haemagglutinin of $\mathrm{M}$. tuberculosis is required for extrapulmonary dissemination. Nature, 412, 190-4 (2001)

56. C. Baldock, A. J. Koster, U. Ziese, M. J. Rock, M. J. Sherratt, K. E. Kadler, C. A. Shuttleworth and C. M. Kielty: The supramolecular organization of fibrillin-rich microfibrils. J Cell Biol, 152, 1045-56 (2001)

57. J. Brandt, T. N. Krogh, C. H. Jensen, J. K. Frederiksen and B. Teisner: Thermal instability of the trimeric structure of the N-terminal propeptide of human procollagen type I in relation to assay technology. Clin Chem, 45, 47-53 (1999)

58. H. Langberg, L. Rosendal and M. Kjaer: Traininginduced changes in peritendinous type I collagen turnover determined by microdialysis in humans. J Physiol, 534, 297-302 (2001)

59. M. J. Rennie and K. D. Tipton: Protein and amino acid metabolism during and after exercise and the effects of nutrition. Аnпu Rev Nutr, 20, 457-83 (2000)

60. S. Rosager, P. Aagaard, P. Dyhre-Poulsen, K. Neergaard, M. Kjaer and S. P. Magnusson: Loaddisplacement properties of the human triceps surae aponeurosis and tendon in runners and non-runners. Scand J Med Sci Sports, 12, 90-8 (2002)

61. E. Gineyts, P. A. Cloos, O. Borel, L. Grimaud, P. D. Delmas and P. Garnero: Racemization and isomerization of type I collagen C-telopeptides in human bone and soft tissues: assessment of tissue turnover. Biochem J, $345 \mathrm{Pt} 3$, 481-5 (2000)

62. H. Langberg, D. Skovgaard, S. Asp and M. Kjaer: Time pattern of exercise-induced changes in type I collagen turnover after prolonged endurance exercise in humans. Calcif Tissue Int, 67, 41-4 (2000)

63. J. R. Robbins and K. G. Vogel: Regional expression of mRNA for proteoglycans and collagen in tendon. Eur $J$ Cell Biol, 64, 264-70 (1994)

64. J. Savolainen, K. Vaananen, J. Puranen, T. E. Takala, J. Komulainen and V. Vihko: Collagen synthesis and proteolytic activities in rat skeletal muscles: effect of castimmobilization in the lengthened and shortened positions. Arch Phys Med Rehabil, 69, 964-9 (1988)

65. J. Savolainen, V. Myllyla, R. Myllyla, V. Vihko, K. Vaananen and T. E. Takala: Effects of denervation and immobilization on collagen synthesis in rat skeletal muscle and tendon. Am J Physiol, 254, R897-902 (1988)

66. F. Edom-Vovard, B. Schuler, M. A. Bonnin, M. A. Teillet and D. Duprez: Fgf4 positively regulates scleraxis and tenascin expression in chick limb tendons. Dev Biol, 247, 351-66 (2002) 
67. A. M. Ahtikoski, S. O. Koskinen, P. Virtanen, V. Kovanen and T. E. Takala: Regulation of synthesis of fibrillar collagens in rat skeletal muscle during immobilization in shortened and lengthened positions. Acta Physiol Scand, 172, 131-40 (2001)

68. A. M. Ahtikoski, S. O. Koskinen, P. Virtanen, V. Kovanen, J. Risteli and T. E. Takala: Synthesis and degradation of type IV collagen in rat skeletal muscle during immobilization in shortened and lengthened positions. Acta Physiol Scand, 177, 473-81 (2003)

69. P. Sharma and N. Maffulli: Tendon injury and tendinopathy: healing and repair. J Bone Joint Surg Am, 87, 187-202 (2005)

70. P. Sharma and N. Maffulli: Basic biology of tendon injury and healing. Surgeon, 3, 309-16 (2005)

71. P. Sharma and N. Maffulli: Biology of tendon injury: healing, modeling and remodeling. $J$ Musculoskelet Neuronal Interact, 6, 181-90 (2006)

72. M. Aumailley and B. Gayraud: Structure and biological activity of the extracellular matrix. $J$ Mol Med, 76, 253-65 (1998)

73. M. Balbin, A. Fueyo, V. Knauper, J. M. Lopez, J. Alvarez, L. M. Sanchez, V. Quesada, J. Bordallo, G. Murphy and C. Lopez-Otin: Identification and enzymatic characterization of two diverging murine counterparts of human interstitial collagenase (MMP-1) expressed at sites of embryo implantation. $J$ Biol Chem, 276, 10253-62 (2001)

74. G. P. Riley, V. Curry, J. DeGroot, B. van El, N. Verzijl, B. L. Hazleman and R. A. Bank: Matrix metalloproteinase activities and their relationship with collagen remodelling in tendon pathology. Matrix Biol, 21, 185-95 (2002)

75. W. Oshiro, J. Lou, X. Xing, Y. Tu and P. R. Manske: Flexor tendon healing in the rat: a histologic and gene expression study. J Hand Surg (Am), 28, 814-23 (2003)

76. C. Erlichman, A. A. Adjei, S. R. Alberts, J. A. Sloan, R. M. Goldberg, H. C. Pitot, J. Rubin, P. J. Atherton, G. G. Klee and R. Humphrey: Phase I study of the matrix metalloproteinase inhibitor, BAY 12-9566. Ann Oncol, 12, 389-95 (2001)

77. N. Ishiguro, T. Ito, K. Obata, N. Fujimoto and H. Iwata: Determination of stromelysin-1, 72 and $92 \mathrm{kDa}$ type IV collagenase, tissue inhibitor of metalloproteinase-1 (TIMP1 ), and TIMP-2 in synovial fluid and serum from patients with rheumatoid arthritis. J Rheumatol, 23, 1599-604 (1996)

78. J. P. Cleutjens, J. C. Kandala, E. Guarda, R. V. Guntaka and K. T. Weber: Regulation of collagen degradation in the rat myocardium after infarction. J Mol Cell Cardiol, 27, 1281-92 (1995)
79. D. H. Manicourt, N. Fujimoto, K. Obata and E. J. Thonar: Levels of circulating collagenase, stromelysin-1, and tissue inhibitor of matrix metalloproteinases 1 in patients with rheumatoid arthritis. Relationship to serum levels of antigenic keratan sulfate and systemic parameters of inflammation. Arthritis Rheum, 38, 1031-9 (1995)

80. A. Passi, D. Negrini, R. Albertini, G. Miserocchi and G. De Luca: The sensitivity of versican from rabbit lung to gelatinase A (MMP-2) and B (MMP-9) and its involvement in the development of hydraulic lung edema. FEBS Lett, 456, 93-6 (1999)

81. R. T. Aimes and J. P. Quigley: Matrix metalloproteinase-2 is an interstitial collagenase. Inhibitorfree enzyme catalyzes the cleavage of collagen fibrils and soluble native type I collagen generating the specific 3/4and 1/4-length fragments. J Biol Chem, 270, 5872-6 (1995)

82. M. L. Patterson, S. J. Atkinson, V. Knauper and G. Murphy: Specific collagenolysis by gelatinase A, MMP-2, is determined by the hemopexin domain and not the fibronectin-like domain. FEBS Lett, 503, 158-62 (2001)

83. S. O. Koskinen, K. M. Heinemeier, J. L. Olesen, H. Langberg and M. Kjaer: Physical exercise can influence local levels of matrix metalloproteinases and their inhibitors in tendon-related connective tissue. $J$ Appl Physiol, 96, 861-4 (2004)

84. C. A. Lambert, C. M. Lapiere and B. V. Nusgens: An interleukin-1 loop is induced in human skin fibroblasts upon stress relaxation in a three-dimensional collagen gel but is not involved in the up-regulation of matrix metalloproteinase 1. J Biol Chem, 273, 23143-9 (1998)

85. J. Archambault, M. Tsuzaki, W. Herzog and A. J. Banes: Stretch and interleukin-1beta induce matrix metalloproteinases in rabbit tendon cells in vitro. J Orthop Res, 20, 36-9 (2002)

86. G. Fassina, N. Ferrari, C. Brigati, R. Benelli, L. Santi, D. M. Noonan and A. Albini: Tissue inhibitors of metalloproteases: regulation and biological activities. Clin Exp Metastasis, 18, 111-20 (2000)

87. Z. Wang, R. Juttermann and P. D. Soloway: TIMP-2 is required for efficient activation of proMMP-2 in vivo. $J$ Biol Chem, 275, 26411-5 (2000)

88. K. E. Kadler, D. F. Holmes, H. Graham and T. Starborg: Tip-mediated fusion involving unipolar collagen fibrils accounts for rapid fibril elongation, the occurrence of fibrillar branched networks in skin and the paucity of collagen fibril ends in vertebrates. Matrix Biol, 19, 359-65 (2000)

89. K. Kami and E. Senba: Localization of leukemia inhibitory factor and interleukin-6 messenger ribonucleic acids in regenerating rat skeletal muscle. Muscle Nerve, 21, 819-22 (1998) 
90. I. M. Ahmed, M. Lagopoulos, P. McConnell, R. W. Soames and G. K. Sefton: Blood supply of the Achilles tendon. J Orthop Res, 16, 591-6 (1998)

91. I. Kolts, B. Tillmann and R. Lullmann-Rauch: The structure and vascularization of the biceps brachii long head tendon. Ann Anat, 176, 75-80 (1994)

92. A. J. Carr and S. H. Norris: The blood supply of the calcaneal tendon. J Bone Joint Surg Br, 71, 100-1 (1989)

93. C. Backman, J. Friden and A. Widmark: Blood flow in chronic Achilles tendinosis. Radioactive microsphere study in rabbits. Acta Orthop Scand, 62, 386-7 (1991)

94. R. Boushel, H. Langberg, J. Olesen, M. Nowak, L. Simonsen, J. Bulow and M. Kjaer: Regional blood flow during exercise in humans measured by near-infrared spectroscopy and indocyanine green. J Appl Physiol, 89, 1868-78 (2000)

95. R. Boushel, H. Langberg, S. Green, D. Skovgaard, J. Bulow and M. Kjaer: Blood flow and oxygenation in peritendinous tissue and calf muscle during dynamic exercise in humans. J Physiol, 524 Pt 1, 305-13 (2000)

96. H. Langberg, J. Bulow and M. Kjaer: Blood flow in the peritendinous space of the human Achilles tendon during exercise. Acta Physiol Scand, 163, 149-53 (1998)

97. H. Langberg, J. Bulow and M. Kjaer: Standardized intermittent static exercise increases peritendinous blood flow in human leg. Clin Physiol, 19, 89-93 (1999)

98. H. Langberg, J. Olesen, D. Skovgaard and M. Kjaer: Age related blood flow around the Achilles tendon during exercise in humans. Eur J Appl Physiol, 84, 2468 (2001)

99. H. Langberg, C. Bjorn, R. Boushel, Y. Hellsten and M. Kjaer: Exercise-induced increase in interstitial bradykinin and adenosine concentrations in skeletal muscle and peritendinous tissue in humans. J Physiol, $542,977-83$ (2002)

100. R. Busse and I. Fleming: Molecular responses of endothelial tissue to kinins. Diabetes, 45 Suppl 1, S8-13 (1996)

101. K. P. O'Kane, D. J. Webb, J. G. Collier and P. J. Vallance: Local L-NG-monomethyl-arginine attenuates the vasodilator action of bradykinin in the human forearm. $\mathrm{Br} J$ Clin Pharmacol, 38, 311-5 (1994)

102. S. E. Barrow, C. T. Dollery, D. J. Heavey, N. E. Hickling, J. M. Ritter and J. Vial: Effect of vasoactive peptides on prostacyclin synthesis in man. Br $J$ Pharmacol, 87, 243-7 (1986)

103. M. L. Honing, P. Smits, P. J. Morrison and T. J. Rabelink: Bradykinin-induced vasodilation of human forearm resistance vessels is primarily mediated by endothelium-dependent hyperpolarization. Hypertension, 35, 1314-8 (2000)
104. R. Boushel, H. Langberg, J. Olesen, J. GonzalesAlonzo, J. Bulow and M. Kjaer: Monitoring tissue oxygen availability with near infrared spectroscopy (NIRS) in health and disease. Scand J Med Sci Sports, 11, 213-22 (2001)

105. R. Boushel, H. Langberg, C. Gemmer, J. Olesen, R. Crameri, C. Scheede, M. Sander and M. Kjaer: Combined inhibition of nitric oxide and prostaglandins reduces human skeletal muscle blood flow during exercise. $J$ Physiol, 543, 691-8 (2002)

106. M. Kjaer, H. Langberg, D. Skovgaard, J. Olesen, J. Bulow, M. Krogsgaard and R. Boushel: In vivo studies of peritendinous tissue in exercise. Scand J Med Sci Sports, 10, 326-31 (2000)

107. A. J. Putnam, K. Schultz and D. J. Mooney: Control of microtubule assembly by extracellular matrix and externally applied strain. Am J Physiol Cell Physiol, 280, C556-64 (2001)

108. S. F. Street: Lateral transmission of tension in frog myofibers: a myofibrillar network and transverse cytoskeletal connections are possible transmitters. J Cell Physiol, 114, 346-64 (1983)

109. A. A. Biewener and T. J. Roberts: Muscle and tendon contributions to force, work, and elastic energy savings: a comparative perspective. Exerc Sport Sci Rev, 28, 99-107 (2000)

110. S. D. Chipman, H. O. Sweet, D. J. McBride, Jr., M. T. Davisson, S. C. Marks, Jr., A. R. Shuldiner, R. J. Wenstrup, D. W. Rowe and J. R. Shapiro: Defective pro alpha 2 (I) collagen synthesis in a recessive mutation in mice: a model of human osteogenesis imperfecta. Proc Natl Acad Sci U S $A, 90,1701-5$ (1993)

111. G. J. Jobsis, H. Keizers, J. P. Vreijling, M. de Visser, M. C. Speer, R. A. Wolterman, F. Baas and P. A. Bolhuis: Type VI collagen mutations in Bethlem myopathy, an autosomal dominant myopathy with contractures. Nat Genet, 14, 113-5 (1996)

112. L. Svensson, A. Aszodi, F. P. Reinholt, R. Fassler, D. Heinegard and A. Oldberg: Fibromodulin-null mice have abnormal collagen fibrils, tissue organization, and altered lumican deposition in tendon. $J$ Biol Chem, 274, 9636-47 (1999)

113. L. Ameye, D. Aria, K. Jepsen, A. Oldberg, T. Xu and M. F. Young: Abnormal collagen fibrils in tendons of biglycan/fibromodulin-deficient mice lead to gait impairment, ectopic ossification, and osteoarthritis. Faseb $J, 16,673-80$ (2002)

114. J. T. Hecht, M. Deere, E. Putnam, W. Cole, B. Vertel, H. Chen and J. Lawler: Characterization of cartilage oligomeric matrix protein (COMP) in human normal and pseudoachondroplasia musculoskeletal tissues. Matrix Biol, 17, 269-78 (1998) 
115. E. G. Canty and K. E. Kadler: Collagen fibril biosynthesis in tendon: a review and recent insights. Comp Biochem Physiol A Mol Integr Physiol, 133, 979-85 (2002)

116. J. E. Scott: Proteoglycan:collagen interactions and subfibrillar structure in collagen fibrils. Implications in the development and ageing of connective tissues. J Anat, 169, 23-35 (1990)

117. J. E. Scott: Structure and function in extracellular matrices depend on interactions between anionic glycosaminoglycans. Pathol Biol (Paris), 49, 284-9 (2001)

118. N. Nakamura, D. A. Hart, R. S. Boorman, Y. Kaneda, N. G. Shrive, L. L. Marchuk, K. Shino, T. Ochi and C. B. Frank: Decorin antisense gene therapy improves functional healing of early rabbit ligament scar with enhanced collagen fibrillogenesis in vivo. J Orthop Res, 18, 517-23 (2000)

119. E. Hedbom and D. Heinegard: Binding of fibromodulin and decorin to separate sites on fibrillar collagens. J Biol Chem, 268, 27307-12 (1993)

120. L. Svensson, I. Narlid and A. Oldberg: Fibromodulin and lumican bind to the same region on collagen type I fibrils. FEBS Lett, 470, 178-82 (2000)

121. Y. Ezura, S. Chakravarti, A. Oldberg, I. Chervoneva and D. E. Birk: Differential expression of lumican and fibromodulin regulate collagen fibrillogenesis in developing mouse tendons. J Cell Biol, 151, 779-88 (2000)

122. J. R. Robbins, S. P. Evanko and K. G. Vogel: Mechanical loading and TGF-beta regulate proteoglycan synthesis in tendon. Arch Biochem Biophys, 342, 203-11 (1997)

123. M. Benjamin, S. Qin and J. R. Ralphs: Fibrocartilage associated with human tendons and their pulleys. J Anat, 187 ( Pt 3), 625-33 (1995)

124. M. Benjamin and J. R. Ralphs: Fibrocartilage in tendons and ligaments--an adaptation to compressive load. J Anat, 193 ( Pt 4), 481-94 (1998)

125. S. L. Felisbino and H. F. Carvalho: Identification and distribution of type VI collagen in tendon fibrocartilages. $J$ Submicrosc Cytol Pathol, 31, 187-95 (1999)

126. A. Rufai, J. R. Ralphs and M. Benjamin: Structure and histopathology of the insertional region of the human Achilles tendon. J Orthop Res, 13, 585-93 (1995)

127. A. Rufai, J. R. Ralphs and M. Benjamin: Ultrastructure of fibrocartilages at the insertion of the rat Achilles tendon. J Anat, 189 ( Pt 1), 185-91 (1996)

128. A. D. Waggett, J. R. Ralphs, A. P. Kwan, D. Woodnutt and M. Benjamin: Characterization of collagens and proteoglycans at the insertion of the human Achilles tendon. Matrix Biol, 16, 457-70 (1998)
129. A. Aroen, D. Helgo, O. G. Granlund and R. Bahr: Contralateral tendon rupture risk is increased in individuals with a previous Achilles tendon rupture. Scand J Med Sci Sports, 14, 30-3 (2004)

130. M. Magra and N. Maffulli: Genetics: does it play a role in tendinopathy? Clin J Sport Med, 17, 231-3 (2007)

131. M. Jarvinen, L. Jozsa, P. Kannus, T. L. Jarvinen, M. Kvist and W. Leadbetter: Histopathological findings in chronic tendon disorders. Scand J Med Sci Sports, 7, 86-95 (1997)

132. G. P. Riley, M. J. Goddard and B. L. Hazleman: Histopathological assessment and pathological significance of matrix degeneration in supraspinatus tendons. Rheumatology (Oxford), 40, 229-30 (2001)

133. C. Tallon, N. Maffulli and S. W. Ewen: Ruptured Achilles tendons are significantly more degenerated than tendinopathic tendons. Med Sci Sports Exerc, 33, 1983-90 (2001)

134. P. Kannus and L. Jozsa: Histopathological changes preceding spontaneous rupture of a tendon. A controlled study of 891 patients. J Bone Joint Surg Am, 73, 1507-25 (1991)

135. G. P. Riley, R. L. Harrall, C. R. Constant, M. D. Chard, T. E. Cawston and B. L. Hazleman: Tendon degeneration and chronic shoulder pain: changes in the collagen composition of the human rotator cuff tendons in rotator cuff tendinitis. Ann Rheum Dis, 53, 359-66 (1994)

136. R. A. Bank, J. M. TeKoppele, G. Oostingh, B. L. Hazleman and G. P. Riley: Lysylhydroxylation and nonreducible crosslinking of human supraspinatus tendon collagen: changes with age and in chronic rotator cuff tendinitis. Ann Rheum Dis, 58, 35-41 (1999)

137. C. M. Lapiere, B. Nusgens and G. E. Pierard: Interaction between collagen type I and type III in conditioning bundles organization. Connect Tissue Res, 5, 21-9 (1977)

138. S. P. Magnusson, K. Qvortrup, J. O. Larsen, S. Rosager, P. Hanson, P. Aagaard, M. Krogsgaard and M. Kjaer: Collagen fibril size and crimp morphology in ruptured and intact Achilles tendons. Matrix Biol, 21, 369-77 (2002)

139. G. P. Riley, R. L. Harrall, C. R. Constant, M. D. Chard, T. E. Cawston and B. L. Hazleman: Glycosaminoglycans of human rotator cuff tendons: changes with age and in chronic rotator cuff tendinitis. Ann Rheum Dis, 53, 367-76 (1994)

140. D. Ireland, R. Harrall, V. Curry, G. Holloway, R. Hackney, B. Hazleman and G. Riley: Multiple changes in gene expression in chronic human Achilles tendinopathy. Matrix Biol, 20, 159-69 (2001)

141. H. Alfredson, M. Lorentzon, S. Backman, A. Backman and U. H. Lerner: cDNA-arrays and real-time quantitative PCR techniques in the investigation of chronic Achilles tendinosis. J Orthop Res, 21, 970-5 (2003) 
142. A. N. Corps, A. H. Robinson, T. Movin, M. L. Costa, D. C. Ireland, B. L. Hazleman and G. P. Riley: Versican splice variant messenger RNA expression in normal human Achilles tendon and tendinopathies. Rheumatology (Oxford), 43, 969-72 (2004)

143. H. Alfredson, S. Forsgren, K. Thorsen and R. Lorentzon: In vivo microdialysis and immunohistochemical analyses of tendon tissue demonstrated high amounts of free glutamate and glutamate NMDAR1 receptors, but no signs of inflammation, in Jumper's knee. J Orthop Res, 19, 881-6 (2001)

144. M. Magra and N. Maffulli: Matrix metalloproteases: a role in overuse tendinopathies. Br J Sports Med, 39, 789-91 (2005)

145. G. Riley: Chronic tendon pathology: molecular basis and therapeutic implications. Expert Rev Mol Med, 7, 1-25 (2005)

Abbreviations: Extracellular Matrix (ECM), glycosaminoglycan (GAG), proteoglycans (PGs), Cartilage oligomeric matrix protein (COMP), Hyaluronan (HA), endoplasmatic reticulum (ER), prolyl-4-hydroxylase (P-4$\mathrm{H})$, galactosylhydroxy-lysyl-glucosyltransferase (GGT), bone morphogenetic protein (BMP-1), pyridinoline (Pyr), HA synthases (HAS), 3'-phosphoadenosine 5'phosphosulfate (PAPS), HS 2-O-sulphotransferase (HS2ST), propeptide of type I collagen (PICP), telopeptide region of type I collagen (ICTP), Magnetic Resonance Imaging (MRI), Matrix Metalloproteases (MMPs), Tissue Inhibitors of Metalloproteases (TIMPs), Membrane type-1 matrix metalloprotease (MT1-MMP), nitric oxide (NO), endothelium derived hyperpolarizing factor (EDHF), knock - out (KO)

Key Words: Tendon, Extracellular matrix, Gene expression, Collagen, Matrix Metalloproteases, Tissue inhibitor of Matrix Metalloproteases, Tendinopathy, Review

Send correspondence to: Alberto Passi, Department of Experimental Biomedical and Clinical Sciences (DSBSC), University of Insubria, Via J.H. Dunant 5, 21100, Varese, Italy, Tel: 0039-0332-217-142, Fax: 0039-0332-217-119, E-mail: alberto.passi@uninsubria.it

http://www.bioscience.org/current/vol2E.htm 